\title{
Genome mining and metabolic profiling of the rhizosphere bacterium Pseudomonas sp. SH-C52 for antimicrobial compounds
}

\section{OPEN ACCESS}

Edited by:

Jesús Mercado-Blanco,

Consejo Superior de Investigaciones

Cientificas, Spain

Reviewed by:

Marta Martín

Universidad Autónoma de Madrid,

Spain

Elizabeth Sattely,

Stanford University, USA

Sandra Matthijs,

Institut de Recherches

Microbiologiques Jean-Marie Wiame,

Belgium

*Correspondence:

Jos M. Raaijmakers,

Department of Microbial Ecology,

Netherlands Institute of Ecology (NIOO-KNAW), Droevendaalsesteeg

10, 6708 PB Wageningen,

Netherlands

j.raaijmakers@nioo.knaw.n

Specialty section: This article was submitted to

Plant Biotic Interactions, a section of the journal Frontiers in Microbiology

Received: 09 April 2015 Accepted: 22 June 2015 Published: 07 July 2015

Citation: Van Der Voort M, Meijer HJG, Schmidt Y, Watrous J, Dekkers E, Mendes $R$

Dorrestein PC, Gross H and

Raaijmakers JM (2015) Genome mining and metabolic profiling of the rhizosphere bacterium Pseudomonas

sp. SH-C52 for antimicrobial compounds. Front. Microbiol. 6:693.

doi: 10.3389/fmicb.2015.00693

\begin{abstract}
Menno Van Der Voort ${ }^{1}$, Harold J. G. Meijer ${ }^{1}$, Yvonne Schmidt ${ }^{2}$, Jeramie Watrous ${ }^{3}$, Ester Dekkers ${ }^{1}$, Rodrigo Mendes ${ }^{1,4}$, Pieter C. Dorrestein ${ }^{3}$, Harald Gross ${ }^{5}$ and Jos M. Raaijmakers ${ }^{1,6 *}$

${ }^{1}$ Laboratory of Phytopathology, Wageningen University, Wageningen, Netherlands, ${ }^{2}$ Institute for Pharmaceutical Biology, University of Bonn, Bonn, Germany, ${ }^{3}$ Departments of Pharmacology and Chemistry and Biochemistry, Skaggs School of Pharmacy and Pharmaceutical Sciences, University of California, San Diego, San Diego, CA, USA, ${ }^{4}$ Brazilian Agricultural Research Corporation, Embrapa Environment, Jaguariuna, Brazil, ${ }^{5}$ Department of Pharmaceutical Biology, Pharmaceutical Institute, University of Tübingen, Tübingen, Germany, ${ }^{6}$ Department of Microbial Ecology, Netherlands Institute of Ecology (NIOO-KNAW), Wageningen, Netherlands
\end{abstract}

The plant microbiome represents an enormous untapped resource for discovering novel genes and bioactive compounds. Previously, we isolated Pseudomonas sp. SH-C52 from the rhizosphere of sugar beet plants grown in a soil suppressive to the fungal pathogen Rhizoctonia solani and showed that its antifungal activity is, in part, attributed to the production of the chlorinated 9-amino-acid lipopeptide thanamycin (Mendes et al., 2011). To get more insight into its biosynthetic repertoire, the genome of Pseudomonas $\mathrm{sp}$. $\mathrm{SH}-\mathrm{C} 52$ was sequenced and subjected to in silico, mutational and functional analyses. The sequencing revealed a genome size of $6.3 \mathrm{Mb}$ and 5579 predicted ORFs. Phylogenetic analysis placed strain $\mathrm{SH}-\mathrm{C} 52$ within the Pseudomonas corrugata clade. In silico analysis for secondary metabolites revealed a total of six non-ribosomal peptide synthetase (NRPS) gene clusters, including the two previously described NRPS clusters for thanamycin and the 2-amino acid antibacterial lipopeptide brabantamide. Here we show that thanamycin also has activity against an array of other fungi and that brabantamide A exhibits anti-oomycete activity and affects phospholipases of the late blight pathogen Phytophthora infestans. Most notably, mass spectrometry led to the discovery of a third lipopeptide, designated thanapeptin, with a 22-amino-acid peptide moiety. Seven structural variants of thanapeptin were found with varying degrees of activity against $P$. infestans. Of the remaining four NRPS clusters, one was predicted to encode for yet another and unknown lipopeptide with a predicted peptide moiety of 8-amino acids. Collectively, these results show an enormous metabolic potential for Pseudomonas sp. SH-C52, with at least three structurally diverse lipopeptides, each with a different antimicrobial activity spectrum.

Keywords: beneficial microbes, rhizosphere bacteria, antimicrobial peptides, Pseudomonads, genome sequencing, mass spectrometry, biocontrol 


\section{Introduction}

Pseudomonas species are ubiquitous in aquatic and terrestrial habitats, and are intensively studied for their abilities to promote plant growth and to suppress plant pathogens (Weller, 2007; Berendsen et al., 2012). The main mechanisms involved in plant pathogen control are induced systemic resistance, competition, antibiosis and parasitism (Van Loon et al., 1998; Haas and Defago, 2005; Van Wees et al., 2008; Lugtenberg and Kamilova, 2009). To date, a wide variety of bioactive compounds involved in pathogen control have been identified for Pseudomonads (Gross and Loper, 2009; Raaijmakers et al., 2010; Raaijmakers and Mazzola, 2012). These include siderophores, hydrogen cyanide, 2,4diacetylphloroglucinol, pyrrolnitrin, pyoluteorin, phenazines, 2,5-dialkylresorcinol, quinolones, gluconic acid, rhamnolipids, and various structurally diverse lipopeptides (Gross and Loper, 2009; D’Aes et al., 2010).

Comparative genomics studies of Pseudomonas species have shown substantial diversity between the genera, between species, and even between strains belonging to the same species (Silby et al., 2011; Wu et al., 2011; Loper et al., 2012; RedondoNieto et al., 2012). Loper et al. (2012) further revealed that most of the genes encoding bioactive compounds map outside the core genome. This includes genes encoding the NonRibosomal Peptide Synthetases (NRPSs). NRPSs possess a modular structure and each module is a building block for the stepwise incorporation of an amino acid in the peptide moiety (Gross and Loper, 2009; Marahiel and Essen, 2009). NRPSs are responsible for the production of an array of antimicrobial compounds including lipopeptides (LPs). Intriguing features of LPs are their enormous structural diversity and diverse natural roles in microbial behavior (Raaijmakers and Mazzola, 2012). By the expansion of available genome sequences also the number of identified NRPS gene clusters has increased considerably over the past years. To exploit the hidden genetic and metabolic potential in genome sequences, a number of search tools and approaches have been developed, including regulatorbased discovery (Hassan et al., 2010), metabolic networking, peptidogenomics and advanced mass spectrometry methods (Kersten et al., 2011; Watrous et al., 2012). This also led to the discovery of NRPS gene clusters involved in the production of structurally novel LPs (Liu et al., 2014).

Recently, we discovered Pseudomonas sp. SH-C52, a strain representative of a larger population of Pseudomonads that contributes to the natural suppressiveness of a soil against the fungal plant pathogen Rhizoctonia solani (Mendes et al., 2011). The gene cluster responsible for the activity of strain SHC52 against $R$. solani is encoded by an NRPS, predicted to synthesize a 9-amino-acid chlorinated LP, designated thanamycin (Mendes et al., 2011). The production and partial structure of thanamycin was resolved by live colony mass spectrometry (Watrous et al., 2012). Next to thanamycin, strain SH-C52 was also found to produce a set of 2-amino-acid LPs, designated brabantamides A-C, which contain a glycosylated 3-hydroxy fatty acid tail. Brabantamide A displays activity against Gram-positive bacteria, including Staphylococcus aureus and Arthrobacter crystallopoietes (Reder-Christ et al., 2012; Schmidt et al., 2014).
The 12-kb gene cluster for brabantamide biosynthesis includes the NRPS gene (braB), a glycosyltransferase (braA) and a specific FAD-dependent Baeyer-Villiger monooxygenase gene (braC). Biosynthesis of brabantamides is complex: a linear dipeptide is formed by $\mathrm{BraB}$ after which the sugar moiety is attached by the glycosyltransferase BraA. This glycosylated dipeptide is subsequently rearranged by the brabantamide-specific monooxygenase BraC (Schmidt et al., 2014).

To extend our knowledge on the biosynthetic repertoire of bioactive compounds of plant-associated Pseudomonas sp. $\mathrm{SH}$ C52, we sequenced the genome and performed detailed in silico as well as metabolomic analyses. Here we show that genomebased phylogeny places strain $\mathrm{SH}-\mathrm{C} 52$ in the Pseudomonas corrugata subgroup of the $P$. fluorescens clade. Next to the known thanamycin and brabantamide gene clusters, in silico analysis revealed four additional NRPS gene clusters. We further characterized the antimicrobial activity spectrum of thanamycin and brabantamide and identified the structure, activity and gene cluster of a novel LP with a 22-amino acid peptide moiety designated thanapeptin.

\section{Materials and Methods}

\section{Strains and Growth Conditions}

The bacterial strains Pseudomonas sp. SH-C52 (Mendes et al., 2011), derivatives from this strain, and Pseudomonas syringae pv. syringae B728a were grown on Pseudomonas agar F (PSA, Difco) or in King's medium B (KB, King et al., 1954). Bacillus megaterium and Pectobacterium atrosepticum SCRI1043 were cultured on Luria Bertani (LB) agar plates or in LB broth. When needed, growth media were supplemented with $25 \mu \mathrm{g} / \mathrm{ml}$ gentamycin $100 \mu \mathrm{g} / \mathrm{ml}$ kanamycin, and/or $25 \mu \mathrm{g} / \mathrm{ml}$ tetracycline. All bacteria were grown at $25^{\circ} \mathrm{C}$.

Mutants in the thanapeptin gene cluster were obtained by screening the transposon insertion mutant library of Pseudomonas sp. SH-C52 for mutants that showed loss of or reduced activity against $R$. solani (Mendes et al., 2011). The initial screening showed the thanapeptin gene cluster mutants (Tn-tnpA and $\operatorname{Tn}-\operatorname{tn} p C$ ) to have a very minor reduction in the growth-inhibitory activity against $R$. solani (data not shown). The site-directed mutants in the thanamycin gene cluster KO25 and $\mathrm{KO} 26$ were obtained previously and were designated in this manuscript as $\mathrm{dThaB}$ and $\mathrm{dThaC} 2$, respectively. All fungi and oomycetes used in this study were cultured on Potato Dextrose Agar (PDA, Difco, Becton, Dickinson and Company, USA), except for Phytophthora infestans strain 88069 and Phytophthora capsici LT3239 which were cultured on Rye Sucrose Medium and on V8 medium (Latijnhouwers et al., 2004), respectively. $P$. infestans was cultured at $18^{\circ} \mathrm{C}$; whereas all other fungi and oomycetes were cultured at $25^{\circ} \mathrm{C}$.

\section{Illumina Genome Sequencing and Assembly}

Illumina sequencing was performed by BGI (China) according to their protocols. For this purpose, two libraries with insert sizes of 0.5 and $\sim 2 \mathrm{~kb}$ were constructed and sequenced. In order to ensure the accuracy of follow-up analysis, several steps were performed to filter the raw data: removal of reads with a certain 
proportion of Ns' bases or low complexity reads ( $10 \%$ as default); removal of reads with a certain proportion of low quality $(\leq \mathrm{Q} 20)$ bases (40 bases as default); removal of adapter contamination (15 bp overlap between adapter and reads as default); removal of contamination due to duplication. For reads with low sequence quality additional processing was performed, i.e., removal of reads with significant poly-A structure, and removal of reads with a k-mer frequency of 1 . During the processing $16 \%$ of the original read data was eliminated. Short reads were assembled into genomic sequences using SOAPdenovo, a BGI developed assembler (Li et al., 2010). Using mapping information gaps were filled and single base pairs were proofread. The usage rate of reads was obtained according to read mapping, from which the genome coverage was estimated.

\section{Additional Sequencing, Sequence Adjustments, and Gene Annotation}

Sequence information on the thanamycin gene cluster from strain SH-C52 (Mendes et al., 2011) was incorporated in the genome sequence to close gaps in the Illumina acquired assembly. In addition, for the predicted 22 amino-acid NRPS gene cluster, gaps were closed by additional standard Sanger sequencing (Macrogen, Amsterdam). Specific primer pairs were designed for PCR to cover the gaps present in the original Illumina assembly (Table S1). Primers were used for both PCR and sequencing. PCR products were sequenced in both orientations. Gene annotation was performed on the complemented genome sequence by use of RAST (http://rast.nmpdr.org) (Overbeek et al., 2014). The genome sequence and gene annotation are available at the NCBI and EMBL database (accession number CBLV000000000).

\section{Genome Analysis and Comparisons}

Genome comparisons were performed by use of nucleotide BLAST (BLASTN) in BioEdit (Ibis Biosciences). Genes identified by Loper et al. (2012) in species from the Pseudomonas fluorescens clade were used for BLASTN analysis on the SH-C52 genome sequence. For Pseudomonas corrugata CFBP5454 (ATKI00000000) and Pseudomonas mandelii JR1 (NZ_CP005960) these analyses were performed online at the NCBI database. In general, genes were considered to be present when more than $65 \%$ identity with the reference sequence(s), and more than $85 \%$ of coverage was observed. In addition to the BLAST analysis, secretion systems were identified by screening gene annotations.

A whole-genome phylogenetic analysis was performed with the genomes of species of the $P$. fluorescens group as reported by Redondo-Nieto et al. (2012), with the addition of the genomes of Pseudomonas corrugata CFBP5454 (ATKI00000000) and P. mediterranea CFBP5447 (AUPB00000000). Phylogenetic trees were built by a Composition Vector approach using the web server CVTree with a $k$-value of 6 (Xu and Hao, 2009). Trees were generated by the Neighbor joining algorithm with $P$. aeruginosa PAO1 as the outgroup. Phylogenetic trees were visualized by MEGA5.1 (MEGA).

For the identification of secondary metabolite gene clusters the genome sequence was analyzed by both the on-line analysis programs NP.searcher (Li et al., 2009) and antiSMASH (Blin et al., 2013).

\section{Thanapeptin Gene Cluster Analysis}

The gene cluster identified to encode a NRPS of 22 amino acids, was further analyzed for the domains in the synthetases by the PKS/NRPS predictor (Bachmann and Ravel, 2009). Moreover, the Adenylation (A)-domains predicted by the PKS/NRPS predictor were analyzed by a phylogenetic comparison to known A-domains. MEGA5.1 (MEGA) was used for alignments and subsequent tree construction, using the neighbor-joining method and 500 bootstrap replicates. The combination of the predictions by NP.searcher, antiSMASH, PKS/NRPS predictor and phylogenetic analysis led to a consensus prediction presented in Figure 5. The first Condensation (C1)-domain predicted for the thanapeptin gene cluster was also subjected to phylogenetic analysis (as described above), with C1-domains of other NRPS gene clusters, to compare the thanapeptin C1-domain to cyclic and non-cyclic (lipo)peptides NRPSs (De Bruijn et al., 2007).

\section{In vitro Inhibition Assays}

For in vitro growth inhibition of fungi and oomycetes, SH-C52 and its derivative strains were, using an overnight culture in $\mathrm{KB}$, spot-inoculated $(3 \mu \mathrm{l})$ at the periphery of $1 / 5$ th strength PDA (pH 7.0) plates. After incubation for 2 days at $25^{\circ} \mathrm{C}$, an agar plug (4-mm-diameter) from a freshly grown plate with the target organism was transferred to the center of the $1 / 5$ th PDA plate. Inhibition of radial growth of the fungus or the oomycete was monitored from 2 days after incubation up to 2 weeks after incubation, depending on the growth speed of the target organism. For in vitro bacteria and yeast inhibition assays, bacteria and yeast cells were included, after autoclaving and cooling to $45^{\circ} \mathrm{C}$, into the $1 / 5$ th PDA medium at a concentration of $\sim 10^{5} \mathrm{cfu} / \mathrm{ml}$. After solidifying and sufficient drying of the plates, $\mathrm{SH}-\mathrm{C} 52$ and its derivative strains were, using an overnight culture in $\mathrm{KB}$, spot-inoculated $(3 \mu \mathrm{l})$ at the periphery of the bacteria or yeast containing plates.

\section{Activity of Brabantamide A Against Phytophthora infestans}

To test both the brabantamide A antimicrobial effect and the effect on phospholipase activity of $P$. infestans, individual $P$. infestans mycelial plugs were transferred to a 24-wells plate (Greiner Bio-One) with each well containing $2 \mathrm{ml}$ rye sucrose broth (Latijnhouwers et al., 2002). Brabantamide A was added to the broth at the concentrations indicated. Brabantamide A was dissolved in DMSO, and DMSO concentrations were normalized for all wells to a final concentration of $1 \%(\mathrm{v} / \mathrm{v})$. Growth of $P$. infestans was monitored for 6-8 days at an incubation temperature of $18^{\circ} \mathrm{C}$. Mycelial mass was determined after drying the mycelium for 2 days at $60^{\circ} \mathrm{C}$. Growth experiments were performed twice, each with two replicates per treatment. As similar results were obtained, representative results of one experiment are shown.

To assay the effect of brabantamide $\mathrm{A}$ on $P$. infestans phospholipid metabolism, mycelial plugs were labeled overnight with $10 \mu \mathrm{Ci}$ carrier free ${ }^{32} \mathrm{PO}_{4}^{3-}$ (GE Healthcare, Diegem, 
Belgium). Brabantamide A treatments were performed simultaneously with the labeling or for $15 \mathrm{~min}$ after the labeling. All treatments contained a final concentration of $1 \%$ $(\mathrm{v} / \mathrm{v})$ DMSO and $0.1 \%(\mathrm{v} / \mathrm{v})$ of $\mathrm{n}$-butanol. The latter was well below phospholipid metabolism stimulatory concentrations (Latijnhouwers et al., 2002) and was included to detect transient PLD activity (Munnik et al., 1995; Meijer et al., 2011). Incubations were halted by addition of perchloric acid (final concentration 5\%) and subsequent freezing in liquid nitrogen. After thawing 3.75 volume of $\mathrm{CHCl}_{3} / \mathrm{CH}_{3} \mathrm{OH} / 1 \mathrm{M}$ $\mathrm{HCl}(50: 100: 1$ by vol) and two glass beads $(\varnothing=3 \mathrm{~mm})$ were added and the samples were again frozen in liquid nitrogen. Samples were thawed and thereafter vigorously shaken for $30 \mathrm{~min}$. Samples were further treated and analyzed as described previously (Latijnhouwers et al., 2002). Radiolabeled phospholipids separated by TLC were detected and quantified by phospho-imaging (Storm, Molecular Dynamics; Sunnyvale, CA, USA).

\section{Mass Spectrometry Analysis}

For NanoDESI experiments the instrument setup was according to Watrous et al. (2012). The nanoDESI source coupled to a Thermo LTQ-FT-ICR MS capable of collision-induced dissociation. All analyses were performed in positive ion mode in the mass range of $\mathrm{m} / z$ from 200 to 2000 . Both the primary and the nanospray capillaries were $150 \mu \mathrm{m}$ o.d. $\times 50 \mu \mathrm{m}$ i.d., with solvent being delivered and removed from the liquid bridge at approximate $45^{\circ}$ angles. The solvent used was acetonitrile $/ 0.05 \%$ formic acid in water (1:1) running at a flow rate of $0.8-2.5 \mu \mathrm{l} / \mathrm{min}$. The droplet size using this configuration was $\sim 200 \mu \mathrm{m}$ in diameter. MALDI imaging was performed according to Liu et al. (2010). For both the MALDI imaging and the NanoDESI experiments, the Pseudomonas sp. SH-C52 and its derivatives were grown on $1 / 5$ th PDA plates.

For antimicrobial assays and detailed MS analysis of the thanapeptin derivatives, strain Pseudomonas sp. SH-C52 was pregrown overnight in $5 \mathrm{ml} \mathrm{LB}$ at $28^{\circ} \mathrm{C}$. This overnight culture was used to streak-inoculate $(10-\mu l$ loop) ISP2 agar plates [ $12 \mathrm{ml} /$ plate, $4 \mathrm{~g} / \mathrm{l}$ yeast extract (Sigma), $4 \mathrm{~g} / \mathrm{l}$ dextrose (Sigma), $10 \mathrm{~g} / 1$ malt extract (Sigma), $7.5 \mathrm{~g} / 1$ agar (Sigma), $7.5 \mathrm{~g} / \mathrm{l}$ agar (Teknova)]. Streak-inoculated plates were grown at $28^{\circ} \mathrm{C}$ for 36-44 h. Thanapeptin was extracted by scraping cells from the plates into solvent $(60 \%$ acetonitrile $/ 40 \%$ water $/ 0.1 \%$ formic acid). Extractions were performed by shaking for $1 \mathrm{~h}$. The cell extract was transferred to $50-\mathrm{ml}$ centrifuge tubes and cells were spun down. The extraction was performed on the same cells for a total of 3 times. The supernatant was dried by rotovap and the pellet was retrieved by rinsing three times of $6 \mathrm{ml}$ of the extraction solvent. The extraction fluid was collected in a centrifuge tube and spun down again. Subsequently, the supernatant was dried by rotovap again using a small 20 -ml scintillation vial until dry. The vial was then rinsed by three washings with $400 \mu \mathrm{l}$ of extraction solvent and placed in a $1.5 \mathrm{ml}$ centrifuge tube and centrifuged at $14,000 \mathrm{rpm}$. The supernatant was injected in the HPLC containing a C18 $4.6 \times 150 \mathrm{~mm} 5 \mu \mathrm{m}$ analytical column with a $250 \mu \mathrm{l}$ sample loop. Mobile phase A was $100 \%$ water with $0.1 \%$ formic acid. Mobile phase B was $100 \%$ acetonitrile with
$0.1 \%$ formic acid. The flow rate was set to $1.0 \mathrm{ml} / \mathrm{min}$ and a gradient elution was used with $15 \%$ mobile phase $\mathrm{B}$ ramped to $95 \%$ mobile phase B over $45 \mathrm{~min}$. The eluent was collected using a fraction collector set to collect $1 \mathrm{ml}$ fractions. Fractions were checked for purity and the right mass using MALDI (Bruker). Purified thanapeptin and its derivatives were subsequently used in antimicrobial assays, and assayed by MS analysis by a Thermo LTQ-FT-ICR MS capable of collision-induced dissociation.

\section{Thanapeptin Activities}

Compounds were tested in interaction with target organisms by different techniques. To test activity against bacteria and the yeast Rhodoturula pilimanae, plates containing the target strain were used. Bacteria and yeast were added at a concentration of $\sim 10^{5} \mathrm{cfu} / \mathrm{ml}$ to the $1 / 5 \mathrm{th}$ PDA medium. After sufficient drying of the plate, filter discs with the test compounds at indicated concentrations were added to the plate. Plates were incubated at $25^{\circ} \mathrm{C}$ and growth was monitored for 4 days. Activity against fungal and oomycete strains was tested both in liquid and on plate. For plate assays, thanapeptin derivatives at a concentration of $50 \mu \mathrm{M}$ were added directly at the border of a $1 / 5$ th PDA, after which an agar plug ( $4 \mathrm{~mm}$ diameter) from a freshly grown plate with the target fungal or oomycete strain was positioned in the center of the plate. Hyphal growth was monitored from 2 days after incubation up to 2 weeks after incubation, dependent on the growth speed. Testing of compound activity against fungal and oomycete strains in liquid culture was performed by addition of the compound to $1 \mathrm{ml}$ of liquid $1 / 5 \mathrm{th} \mathrm{PDB}$ in a 12 wells culture plate (Greiner Bio-One), in which an agar plug $(4 \mathrm{~mm}$ diameter) from a freshly grown plate with the target organism was submerged. Growth experiments were incubated at $25^{\circ} \mathrm{C}$, except for $P$. infestans, which was cultured at $18^{\circ} \mathrm{C}$.

\section{Results}

\section{General Genome Features and Phylogeny}

Sequencing and assembly showed that the genome size of Pseudomonas sp. SH-C52 is $\sim 6.3 \mathrm{Mb}$ with a GC content of $61.0 \%$. The genome was assembled in 596 contigs and 25 scaffolds, with an estimated coverage of $99.2 \%$. For annotation, 384 contigs of at least 100-bp and covering 6.3 MB were used. In total, 5579 ORFs were annotated with 5523 CDSs and 56 tRNAs (Table 1). Previous analysis of the 16S rRNA sequence placed SH-C52 within the $P$. fluorescens clade (Mendes et al., 2011). At that time, however, no conclusive species designation was obtained. Expanding the former genome-wide phylogenetic analysis on P. fluorescens species (Redondo-Nieto et al., 2012) with the SH-C52 genome and the recent draft genomes of $P$. corrugata CFBP5454 and P. mediteranea CFBP5447, showed that strain SH-C52 clusters within subgroup I of the P. fluorescens group. Within subgroup I, SH-C52 and the strains of $P$. corrugata and $P$. mediterranea form a separate clade (Figure 1).

\section{In silico Analysis of Pseudomonas sp. SH-C52 Primary Metabolism}

The metabolic potential of Pseudomonas sp. SH-C52 was analyzed by comparing genes from primary metabolism with 
TABLE 1 | General genome sequence information of Pseudomonas sp. SH-C52.

\begin{tabular}{lcc}
\hline & Scaffold & Contig > 100 bp \\
\hline Number & 25 & 384 \\
Total Length (bp) & $6,356,481$ & $63,12,590$ \\
Max length (bp) & $1,572,034$ & 292,658 \\
Min length (bp) & 505 & 102 \\
Sequence GC(\%) & 61.0 & 61.0 \\
Gene number & 5808 & 5579 \\
tRNAs & 55 & 56
\end{tabular}

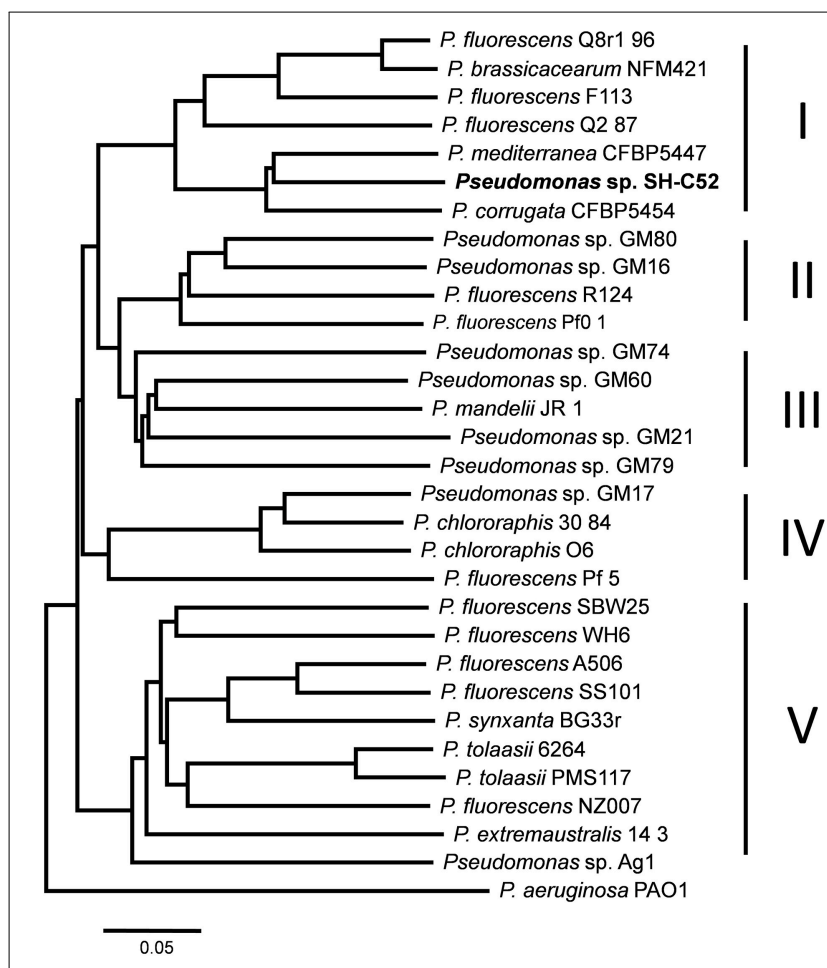

FIGURE 1 | Whole genome phylogenetic analysis of Pseudomonas sp. SH-C52. Phylogenetic tree constructed by use of CVtree, and based on the analysis performed previously by Redondo-Nieto et al. (2012), with the addition of strains SH-C52, P. corrugata CFBP5454 and P. mediterranea CFBP5447.

those known for the P. fluorescens clade (Loper et al., 2012). In this analysis, also its close relative $P$. corrugata strain CFBP5454 was included as well as $P$. mandelii strain JR-1 as a representative strain for subgroup III. The comparative analysis showed that for several of the metabolic activities in species of the $P$. fluorescens clade, the gene sequences are also found in strain SH-C52. These include genes involved in catabolism of $\mathrm{L}$-arabinose, mannitol, myo-inositol, and ethanol, as well as genes coding for gelatinase and lipase. The ethanol catabolism genes, however, were only detected in five of the 12 other studied strains of the P. fluorescens clade, including subgroup I strains Q8r1-96, Q2-87, and P. corrugata CFBP5454. In contrast, genes encoding catabolic pathways for trehalose (10 strains), levan sucrase (7 strains) and L-tryptophan (7 strains, only subgroup IV and V) are present in multiple strains of the $P$. fluorescens clade, but were not detected in the SH-C52 genome (Table 2). Interestingly, comparing the $\mathrm{SH}$-C52 genes with genes in the genome of P. corrugata CFBP5454 showed a few remarkable differences. Genes for trehalose catabolism were found in P. corrugata but not in SH-C52. The same was found for the nitrate reductase gene cluster previously reported for $P$. corrugata strains (Siverio et al., 1993). These differences in the presence of genes involved in primary metabolism further strengthen the phylogenetic delineation (Figure 1) where SH-C52 is closely related to, but different from P. corrugata.

\section{Genome Analysis of Traits Involved in Plant-microbe Interactions}

In silico analysis of the SH-C52 genome for genes involved in the production of phytohormones, volatiles, and plant signaling compounds led to the identification of putative pathways for acetoin/butanediol and for GABA catabolism (Table 3). Also the different bacterial secretion systems are of crucial importance for plant-microbe interactions (Korotkov et al., 2012; Russell et al., 2014; Tampakaki, 2014). The genome of SH-C52 contains two gene clusters encoding type II secretion systems with significant sequence similarity $(>70 \%)$ to the Xcp and Hxc systems of $P$. aeruginosa (Table 3). Genes encoding potential substrates of the type II secretion system, such as lipases, proteases, esterases and alkaline phosphatases (Douzi et al., 2012) are well presented in the SH-C52 genome (Tables 2, 3). No genes encoding a type III secretion system were found in the SH-C52 genome, yet two putative effector genes for this secretion system were identified (BN844_1916 and BN844_3678). Type VI secretion systems are conserved among Gram-negative bacteria and are thought to be involved in bacteria-bacteria interactions (Russell et al., 2014). Two gene clusters were found to encode type VI secretion systems of which one (BN844_4205-4227) was typed as a HSII locus and the second (BN844_0760-0774) as a HSI-III locus (Table 3).

\section{Genome Analysis for Secondary Metabolites}

To predict putative secondary metabolites, such as antibiotics, siderophores and other NRPS genes, the genome sequence was first screened by BLAST for ORFs of known compounds produced by other species and strains of the $P$. fluorescens clade (Loper et al., 2012). Only five SH-C52 clusters corresponded with known clusters (Table 3). First of all, the gene cluster for hydrogen cyanide production (HCN, BN844_0823-0821) was found in the SH-C52 genome and corresponded to the gene cluster found in eight out of the 10 previously sequenced Pseudomonas species (Loper et al., 2012). No pyoverdine synthetase gene cluster was found in $\mathrm{SH}-\mathrm{C} 52$, which was also the case for $P$. corrugata. This corresponds to the observation that $P$. corrugata strains are known to be pyoverdine negative (Meyer et al., 2002). The siderophore gene cluster identified for SH-C52 is achromobactin (BN844_0513-0523). This gene cluster is not common among members of the $P$. fluorescens species clade, but has been described for $P$. syringae strains (Berti and Thomas, 2009; Owen and Ackerley, 2011) and for two P. chlororaphis strains (Loper et al., 2012), and is also found in the 
TABLE 2 | Primary metabolism and corresponding genes of Pseudomonas SH-C52.

\begin{tabular}{|c|c|c|c|c|c|c|c|c|c|c|c|c|c|}
\hline \multirow[t]{2}{*}{ Function } & \multicolumn{4}{|c|}{ I } & \multirow{2}{*}{$\frac{\text { II }}{\text { Pf0-1 }}$} & \multirow{2}{*}{$\frac{\text { III }}{\text { Pm JR-1 }}$} & \multicolumn{3}{|c|}{ IV } & \multicolumn{4}{|c|}{$\mathbf{V}$} \\
\hline & SH-C52 & Pc 5454 & Q8r1-96 & Q2-87 & & & Pf-5 & $30-84$ & 06 & SBW25 & A506 & SS101 & BG33R \\
\hline Gelatinase & BN844_0247 & 0 & $\mathbf{0}$ & o & 0 & $\mathbf{0}$ & 0 & 0 & 0 & 0 & 0 & o & 0 \\
\hline Lipase & BN844_0271 & 0 & $\mathbf{0}$ & o & 0 & $\mathbf{0}$ & o & o & 0 & 0 & 0 & 0 & 0 \\
\hline Phenylacetic acid & & & & & & & 0 & o & 0 & & & & \\
\hline Sodium Benzoate & & & $\mathbf{0}$ & & 0 & $\mathbf{0}$ & 0 & o & 0 & & & o & \\
\hline Trehalose & & $\mathbf{0}$ & $\mathbf{0}$ & & & $\mathbf{0}$ & $\mathbf{0}$ & o & 0 & $\mathbf{0}$ & $\mathbf{0}$ & $\mathbf{0}$ & 0 \\
\hline Levan sucrase & & & 0 & $\mathbf{0}$ & & & & o & 0 & 0 & 0 & 0 & \\
\hline L-arabinose & BN844_3151-3149 & 0 & 0 & o & 0 & o & & o & 0 & 0 & 0 & 0 & 0 \\
\hline Nitrate reduction & & 0 & $\mathbf{0}$ & $\mathbf{0}$ & & $\mathbf{0}$ & & & 0 & & & & \\
\hline D-serine & & & & & & & & o & 0 & & & & \\
\hline Denitrification & & 0 & 0 & o & & $\mathbf{0}$ & & & & & & & \\
\hline Ethanol & BN844_0564 & 0 & $\mathbf{0}$ & 0 & & 0 & 0 & & & & & & \\
\hline Sorbitol & & & o & o & & $\mathbf{0}$ & & & & 0 & 0 & 0 & 0 \\
\hline Mannitol & BN844_0168 & 0 & $\mathbf{0}$ & 0 & 0 & $\mathbf{0}$ & 0 & o & 0 & 0 & $\mathbf{0}$ & o & 0 \\
\hline myo-Inositol & BN844_0814 & 0 & $\mathbf{0}$ & $\mathbf{0}$ & & $\mathbf{0}$ & 0 & o & 0 & 0 & 0 & o & 0 \\
\hline D-xylose & BN844_0249 & 0 & 0 & o & 0 & o & & & & 0 & 0 & 0 & 0 \\
\hline L-tryptophan & & & & & & & 0 & o & 0 & 0 & 0 & 0 & 0 \\
\hline
\end{tabular}

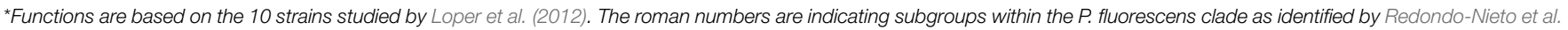

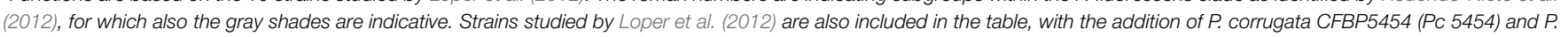
mandelii JR-1 (Subgroup III). For SH-C52 the locus tags for the corresponding genes are given.

genome of $P$. corrugata strain CFBP5454 (WP_024777665-670, Table 3). In addition to the achromobactin gene cluster, an NRPS gene cluster (BN844_2194-2167) was identified with similarity to genes presumably involved in ornicorrugatin biosynthesis. The putative (orni)corrugatin gene cluster identified in $\mathrm{SH}$ C52 was also found in P. fluorescens strains Q8r1-96 and SBW25. Ornicorrugatin and the related compound corrugatin are so-called secondary siderophores (Matthijs et al., 2008). For $P$. fluorescens, however, conclusive experiments that link the production of (orni-) corrugatin to its putative gene cluster are still lacking.

Two other gene clusters in SH-C52 were predicted to encode insecticidal toxins. The first gene cluster is related to the Tcc2 toxin for which the genes are also found in the genomes of P. fluorescens strains Q8r1-96 and Q2-87. The second insect toxin gene cluster is similar to that of Tcc4 toxin (Table 3). No bacteriocin gene clusters could be identified with similarity to those found in other genomes of the P. fluorescens clade. However, a prophage gene cluster (BN844_3382-3419) flanked by $\operatorname{cin} A$ and mutS, typical for prophages present in other Pseudomonas genomes (Loper et al., 2012), was identified in the genome of SH-C52.

\section{Non-ribosomal Peptide Synthetases}

The SH-C52 genome contains six NRPS gene clusters, including the putative (orni-) corrugatin gene cluster (Figure 2). The other five clusters include the known NRPS gene clusters for the synthesis of thanamycin (BN844_0670-0673 and BN844_0703-0704, Mendes et al., 2011), and brabantamide (BN844_0705-0707, Schmidt et al., 2014). In close proximity to the thanamycin and brabantamide gene clusters, a third
NRPS gene cluster (BN844_0667-0664) was identified (Figure 2). This NRPS is predicted to code for a 22 aminoacid lipopeptide with similarity to corpeptin (Figure 2 ) produced by $P$. corrugata. Therefore, in agreement with the naming of cormycin and corpeptin, we designated the predicted 22amino-acid compound of SH-C52 as thanapeptin. The genome of $P$. corrugata CFBP5454 contains several NRPS genes with similarity to the 22 amino-acid related gene cluster in SH-C52. However, in P. corrugata this gene cluster is divided over different contigs. Recently, a partial gene cluster containing a partial NRPS gene, encoding two adenylation-domains and two transport genes, were linked to corpeptin production (Strano et al., 2014). Because of the incomplete nature of the draft genome sequence for strain CFBP5454, it remains unclear if the organization of the gene clusters for cormycin and corpeptin of $P$. corrugata is also similar to that of thanamycin and thanapeptin in SH-C52. However, consistent with the gene organization in $\mathrm{SH}-\mathrm{C} 52$, a putative brabantamide-like gene cluster was also found in $P$. corrugata down-stream of the putative cormycin gene cluster (Figure 2). In addition, the biocontrol strain $P$. fluorescens In5 was recently reported to produce the antagonistic metabolites nunamycin and nunapeptin, also with similarity to cormycin and corpeptin, respectively. Although gene clusters for nunamycin and nunapeptin were presented (Michelsen et al., 2015), the genome information of strain In5 was not provided.

The fourth NRPS gene cluster (BN844_0379-0382) found in $\mathrm{SH}-\mathrm{C} 52$ is predicted to code for an NRPS that produces an 8amino-acid lipopeptide, with no significant similarity to other known compounds in general and dedicated databases such as NCBI and the Norine peptide database. This gene cluster 
TABLE 3 | Secondary metabolite production and corresponding genes of Pseudomonas sp. SH-C52.

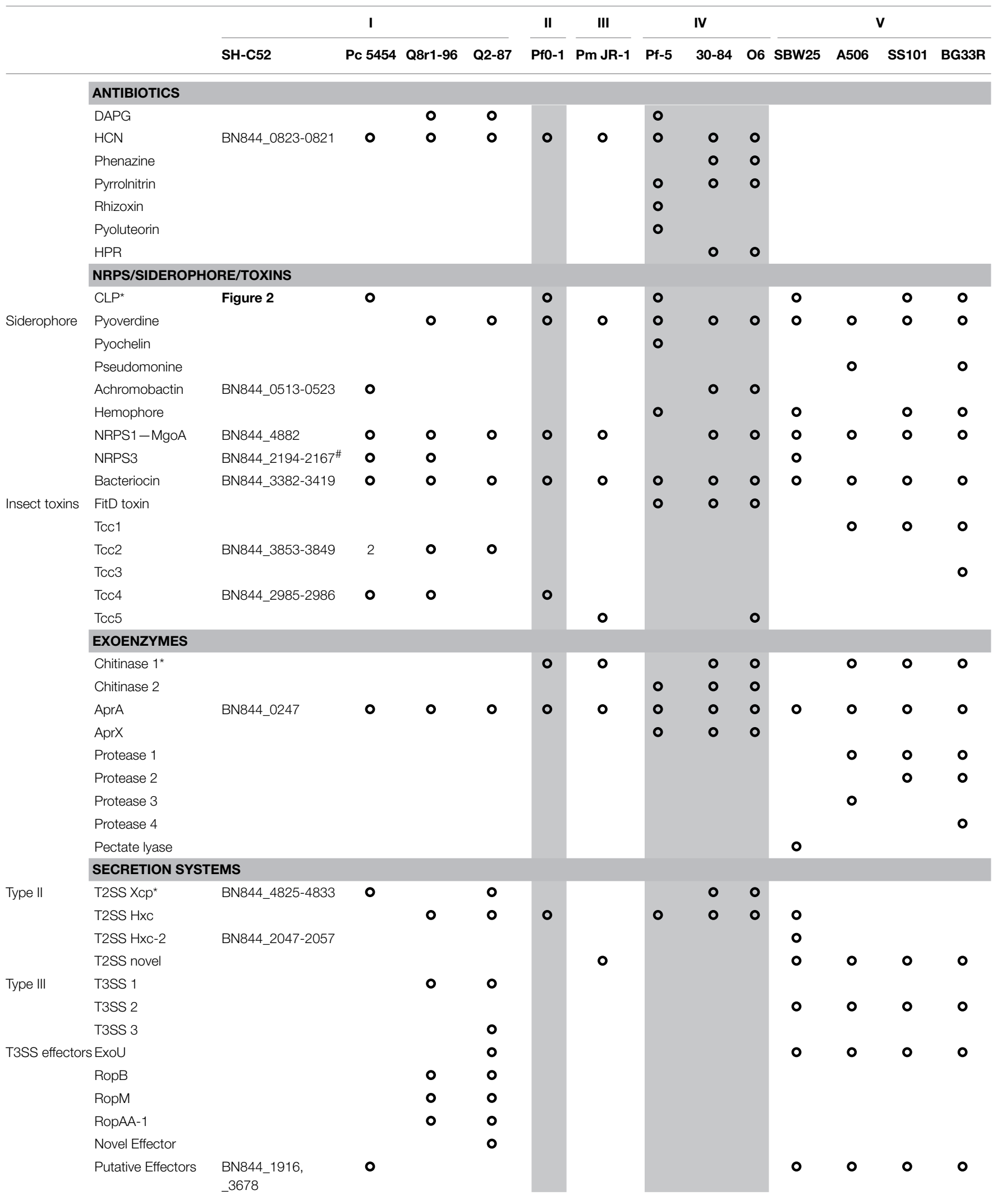




\begin{tabular}{|c|c|c|c|c|c|c|c|c|c|c|c|c|c|c|}
\hline & & \multicolumn{4}{|c|}{1} & $\frac{\text { II }}{\text { Pf0-1 }}$ & $\frac{\text { III }}{\text { Pm JR-1 }}$ & \multicolumn{3}{|c|}{ IV } & \multicolumn{4}{|c|}{$\mathbf{v}$} \\
\hline & HSI-II & & 0 & & 0 & o & 0 & & o & 0 & & $\mathbf{0}$ & 0 & o \\
\hline & HSI-III & BN844_0760-0774 & 0 & $\mathbf{0}$ & 0 & $\mathbf{0}$ & & & & & & & & \\
\hline & TSS4 & & & & & & & & & 0 & & & & \\
\hline & IAA biosynthesis & & & & & & & & 0 & 0 & & & & \\
\hline & IAA catabolism & & & & & & & & & & & & & o \\
\hline & PAA catabolism & & & & & & & o & o & 0 & & & & \\
\hline & ACC deaminase & & & 0 & & & & & & & & & & \\
\hline & Butanediol synthesis & & & & & & & o & o & o & & & & \\
\hline
\end{tabular}

*Functions are based on the 10 strains studied by Loper et al. (2012). The roman numbers are indicating subgroups within the P. fluorescens clade as identified by Redondo-Nieto et al. (2012), for which also the gray colors are indicative. Strains studied by Loper et al. (2012) are also included in the table, with the addition of P. corrugata CFBP5454 (PC 5454) and P. mandelii JR-1 (Subgroup III). For SH-C52, the locus tags for the corresponding genes are given. Cyclic lipopeptides (CLP) for SH-C52 are discussed in the text and listed in Figure 2. \#The SH-C52 NRPS3-corrugatin gene cluster sequence is incomplete and divided over different contigs.

appears to be unique for $\mathrm{SH}-\mathrm{C} 52$, as it was not found in other genomes. The last NRPS gene cluster identified in SH-C52 shows similarity to $m g o A$-like gene clusters, encoding only one adenylation domain. MgoA or MgoA-regulated compound(s) were proposed to regulate the expression of pathogenicity factors in P. entomophila and P. syringae (Vallet-Gely et al., 2010; Carrion et al., 2014), although the underlying mechanism is yet unknown.

\section{Thanamycin: Gene Cluster and Antimicrobial Activity}

Based on mutant analysis, the thanamycin gene cluster was shown to be important for the growth-inhibitory activity of strain SH-C52 against Rhizoctonia solani (Mendes et al., 2011). The thanamycin gene cluster shows similarity to a fragmented NRPS gene cluster in P. corrugata CFBP5454 (Figure 2), but the incomplete and scattered $P$. corrugata sequences complicate a clear comparison between the thanamycin and cormycin gene clusters. Alignments of the thanamycin NRPSs and the annotated parts of cormycin NRPSs show $85-97 \%$ protein identity. To test the antimicrobial activity-spectrum of thanamycin, wild type SH-C52 and two thanamycin biosynthesis mutants (Mendes et al., 2011) were tested for activity against fungi, oomycetes and bacteria. Here, we show that the activity spectrum of thanamycin is not exclusive for R. solani, but extends to an array of other fungi (Figure 3) and the Gram-positive bacterium Bacillus megaterium (data not shown). Also cormycin has been shown to be active against $B$. megaterium and the yeast Rhodotorula pilimanae (Scaloni et al., 2004). In contrast, thanamycin has little activity against oomycete pathogens (Figure 3) and the Gram-negative bacteria Pseudomonas syringae and Pectobacterium atrosepticum (data not shown).

\section{Brabantamide: Gene Cluster and Antimicrobial Activity}

The gene cluster and the brabantamide compounds were previously identified (Schmidt et al., 2014). Interestingly, a putative brabantamide gene cluster is also present in the genome of $P$. corrugata (Figure 2) as well as in the genome of $P$. fluorescens DSM 11579 (Johnston et al., 2013).

In previous studies, brabantamides were shown to have activity against specific Gram-positive bacteria (Reder-Christ et al., 2012; Schmidt et al., 2014). Here, we show that brabantamide $\mathrm{A}$, at a concentration of $50 \mu \mathrm{M}$, has activity against the oomycete plant pathogens Phytophthora capsici, Pythium ultimum, and $P$. infestans (Figure 4). No antifungal activity was observed at this concentration (data not shown). For P. infestans, mycelial growth was already inhibited at concentrations above $5 \mu \mathrm{M}$ resulting in a less dense mycelial mat (Figure 4A). Previous studies suggested that structural analogs of brabantamide A inhibit phospholipase A2 of rabbit (Thirkettle et al., 2000). When $\left[{ }^{32} \mathrm{P}\right]$ Pi-labeled hyphae of $P$. infestans were incubated for $15 \mathrm{~min}$ with brabantamide, no significant variation in the phospholipid levels was observed (data not shown). However, overnight exposure of $P$. infestans mycelium to brabantamide A led to an increase in the phosphatidylbutanol (PtdBut) levels. This already occurred at a concentration of $1 \mu \mathrm{M}$ brabantamide $\mathrm{A}$, the lowest concentration tested (Figure 4). Other phospholipid levels were not affected based on quantification. The enhanced PtdBut levels indicates a stimulatory effect of brabantamide A on phospholipase $\mathrm{D}$ activity. In contrast, no indication was found for the inhibition of phospholipase A2 in this assay. 


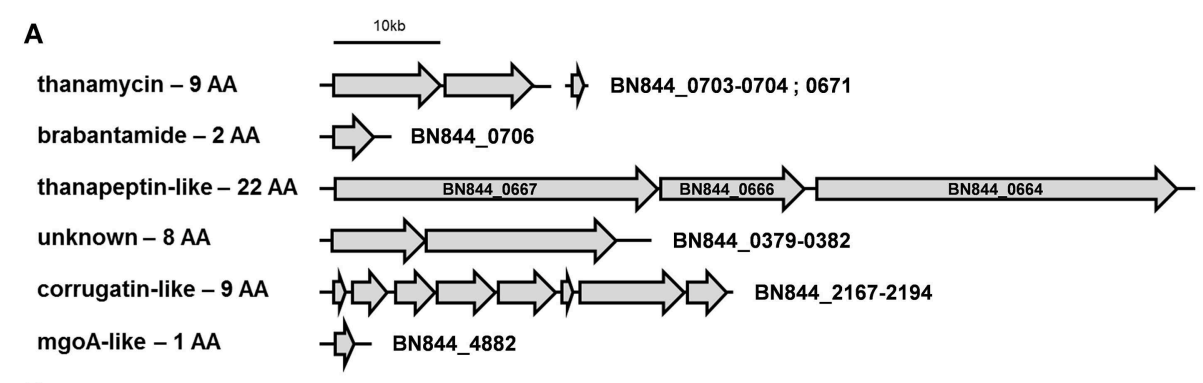

B

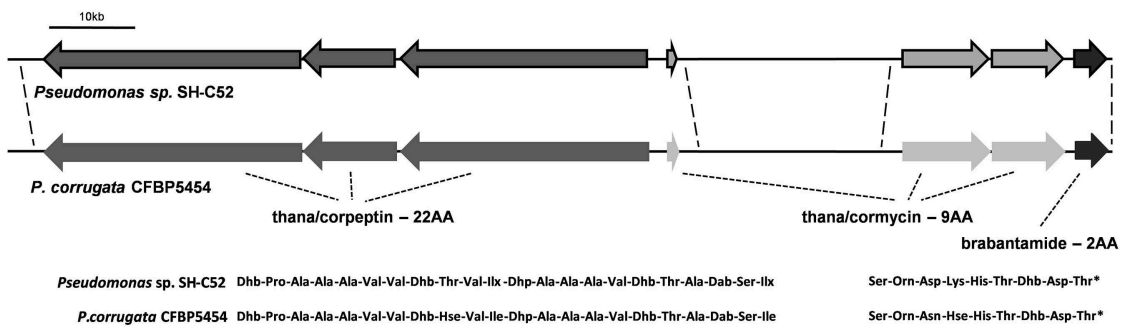

FIGURE 2 | Non-ribosomal peptide synthetase gene clusters present in the genome of Pseudomonas sp. SH-C52. (A) The six NRPS gene clusters predicted in the genome of SH-C52. (B) A comparison of the $\mathrm{SH}-\mathrm{C} 52$ thanamycin-thanapeptin-brabantamide cluster with the putative equivalent cluster of $P$. corrugata CFBP5454. Thana/corpeptin related NRPS genes are in dark gray, thana/cormycin NRPS genes are in light gray, and brabantamide genes are in near black. The $P$. corrugata genes are not bordered, as the genome information is scattered over contigs and needs to be confirmed. Dotted lines indicate (expected) sequence conservation. Amino acids are indicated in their standard three-letter annotation. Non-standard amino acids were abbreviated as follows: Hse, homoserine; Ix, isoleucine or leucine; Dab, 2,4-diaminobutanoic acid; Dhb, 2,3-dehydro2-aminobutanoic acid; Dhp, dehydro-2-aminopropanoic acid (dehydroalanine). The asterisk in the thana/cormycin structure indicates chlorination of this amino acid.

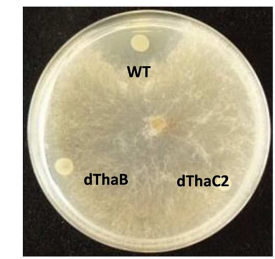

R. solani

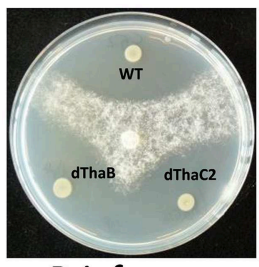

P. infestans

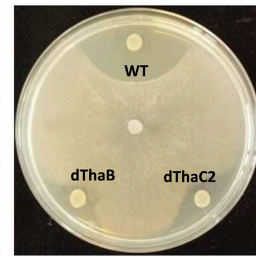

B. cinerea

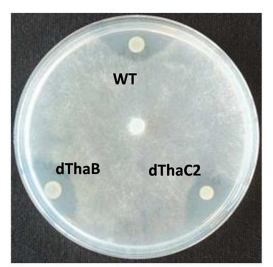

P. ultimum

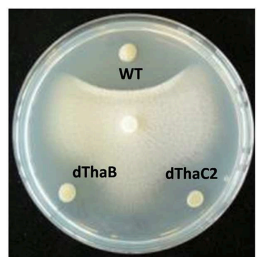

Geotrichum sp.

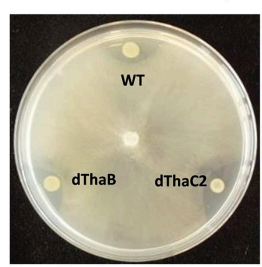

P. capsici
FIGURE 3 | Antagonistic activity of Pseudomonas sp. SH-C52. Wild-type (WT) and the thanamycin mutant strains (ThaB, ThaC2) were tested in dual culture assays for activity against fungal plant pathogens (upper panel) and oomycete plant pathogens (lower panel).

\section{Thanapeptin: Gene Cluster, Structural Analysis and Antimicrobial Activity}

The thanapeptin gene cluster consists of three NRPS genes. BLAST analysis of the protein sequences showed similarity with the NRPSs for the production of the LP syringopeptin of $P$. syringae. Indeed, the first gene of the thanapeptin cluster starts with a specific condensation (C)-domain, a socalled C1 starter domain (data not shown), suggesting $N$ acylation of the first amino acid in the peptide moiety. The three NRPS genes of the thanapeptin gene cluster encode nine, four and nine adenylation (A)-domains, respectively. The prediction of the 22 amino acids activated by these A-domains is shown in Figure 5. The C-terminus of the last gene of the cluster encodes two thioesterase (TE)-domains, indicating termination of the thanapeptin synthesis. Despite the similarity between syringopeptin and thanapeptin (Figure 2), there also is a clear difference in modular organization as syringopeptin is produced from three NRPS modules, with five, five and twelve adenylation domains, respectively. Comparison with the P. corrugata CFBP5454 draft genome sequence shows that the corpeptin gene cluster sequence is incomplete and scattered over contigs. Nevertheless, for the annotated parts, protein identities with the SH-C52 NRPSs ThpA and ThpC ranged between 75 and 95\%, whereas for ThpB identities ranged between 60 and $80 \%$.

Using MALDI and live colony NanoDESI mass spectrometry, a specific group of ions was detected for which the parent mass ranged from 2082 to $2150 \mathrm{Da}$. Comparing the tandem MS spectra of this set of ions indicated these are related peptides, probably produced by the same NRPS gene cluster. Usage of the peptidogenomics approach (Kersten et al., 2011) on the tandem MS data of these ions (Supplementary Data) revealed that they can be linked to the predicted thanapeptin peptide sequence, and thus to the thanapeptin NRPS gene cluster. MS analysis of the extracts from the thanapeptin mutants indeed showed that the 
A

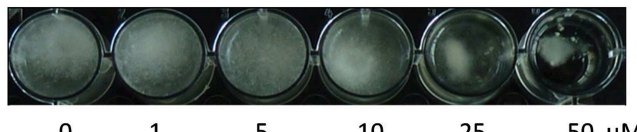

C
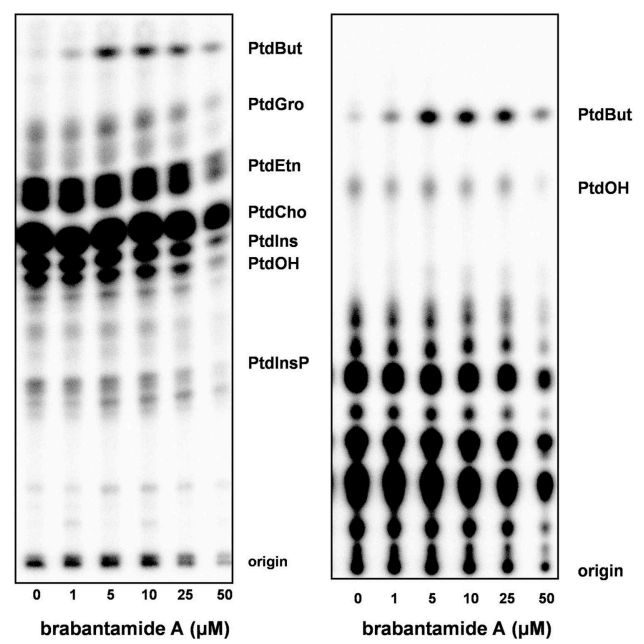

B

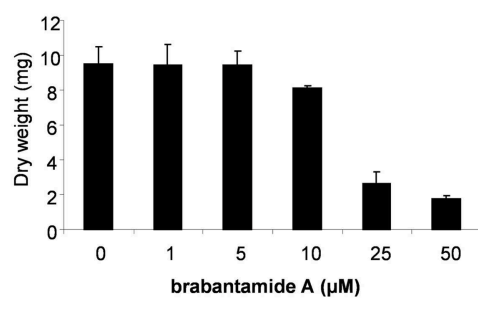

D

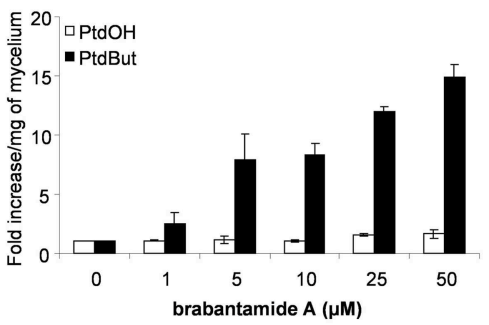

FIGURE 4 | Antimicrobial and phospholipase D stimulating activity of brabantamide $A$ in interaction with Phytophthora infestans.

(A) Growth of $P$. infestans in liquid medium with different concentrations of brabantamide A. (B) Dry weight of $P$. infestans grown in liquid medium $(n=2)$. (C) Lipids extracted from $P$. infestans, separated by alkaline (left) or ethylactetate (EtAC) TLC (right) and analyzed by phosphoimaging. The origin of the chromatogram, phosphatidylinositolphosphate (PtdlnsP), phosphatidic acid (PtdOH), phosphatidylinositol (Ptdlns), phosphatidylcholine (PtdCho), phosphatidylethanolamine (PtdEtn), phosphatidylglycerol (PtdGro) and phosphatidylbutanol (PtdBut) are indicated. (D) PtdOH and PtdBut were quantified from the EtAc TLC and presented as the fold increase when compared to control conditions $(n=2)$. Error bars represent standard deviations. production of all ions of the putative thanapeptin group were absent (data not shown). Further analysis of the tandem MS data of the subsequently purified ion of $2120 \mathrm{Da}$ was in agreement with the in silico predicted amino acid sequence for thanapeptin. In addition, tandem MS data provided evidence for cyclization, and resolved the identity of the lipid moiety of thanapeptin (Figure 5 and Supplementary Presentation 1).

The role of the thanapeptin gene cluster in the activity of SH-C52 against fungi, oomycetes and bacteria was studied by comparing wild-type strain $\mathrm{SH}-\mathrm{C} 52$ and two independent mutants, each with a single transposon insertion in the thanapeptin NRPS gene cluster. The two mutants lost their antagonistic activity against oomycete pathogens, whereas they still had activity against fungi (Figure 6) and bacteria (data not shown). From the wild-type strain, thanapeptin derivatives were purified and seven derivatives were tested for activity against the oomycete $P$. infestans. Substantial differences in anti-oomycete activity were observed between the compound derivatives, with the strongest activity for those with the lowest mass, i.e., compounds with the masses 2082, 2096, 2108, and $2122 \mathrm{Da}$ (Figure 7A). In addition, two derivatives with strong activity, 2096 and $2122 \mathrm{Da}$, were also tested against the oomycete pathogens Saprolegnia parasitica and P. ultimum. Similar results were obtained as in the assays with $P$. infestans, with the strongest activity for the derivative with a mass of $2096 \mathrm{Da}$, and slightly lower activity for the derivative with a mass of $2122 \mathrm{Da}$ (data not shown). Subsequently, the activity of the derivative with a mass of 2096 Da was tested at different concentrations against the three oomycete pathogens in a liquid broth. For $P$. infestans (Figure 7), a clear reduction in mycelial growth was observed at a concentration of $0.25 \mu \mathrm{g} / \mathrm{ml}$. For syringopeptin or corpeptin, no anti-oomycete activity has been reported to date (Vassilev et al., 1996; Emanuele et al., 1998). No apparent antifungal activity or activity against Gram-negative bacteria was observed for any of the thanapeptin derivatives, whereas activity was observed against the Gram-positive bacterium B. megaterium (data not shown), which is in line with results observed previously for syringopeptin and corpeptin (Vassilev et al., 1996; Emanuele et al., 1998).

\section{Discussion}

Pseudomonas sp. SH-C52 was initially studied for its role in the natural soil suppressiveness against the fungal pathogen $R$. solani (Mendes et al., 2011). Here we show by both genome and metabolomic analyses that this plant-associated bacterium has a much greater genomic capacity for the production of secondary metabolites. We showed that Pseudomonas sp. SH-C52 can be placed within subgroup I of P. fluorescens species (RedondoNieto et al., 2012) as a separate clade together with $P$. corrugata and $P$ mediterranea. $P$. corrugata strains have been reported for biological control, for bioremediation and for the production of a range of biomolecules. In contrast, $P$. corrugata strains have also been reported as plant pathogenic bacteria (Catara, 2007). 
A

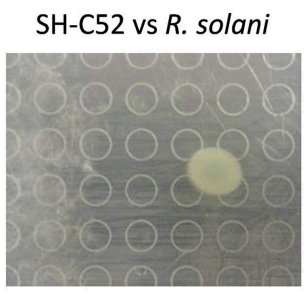

B

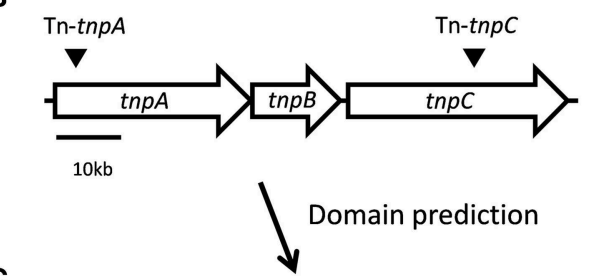

$\mathrm{m} / \mathrm{z} 1291.63$

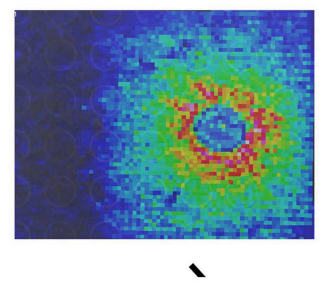

Thanamycin

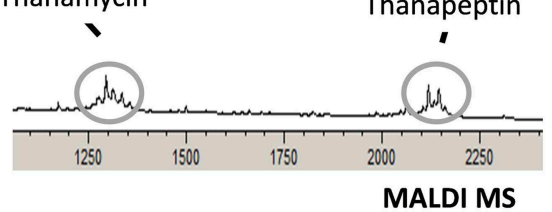

C

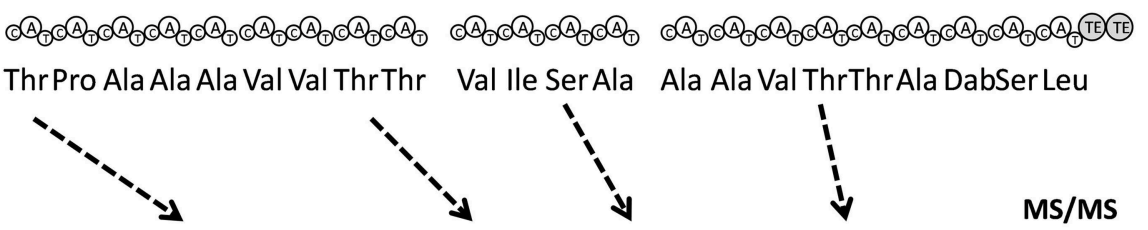

(3-OH-decanoyl)-Dhb-Pro-Ala-Ala-Ala-Val-Val-Dhb-Thr-VaHIlx-Dhp-Ala-Ala-Ala-VatDhb-Thr-Ala-Dab-Ser-Ilx

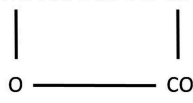

FIGURE 5 | Thanapeptin genetic and chemical analysis. (A) The upper panel shows the interaction of SH-C52 in interaction with $R$. solani, as imaged by MALDI imaging mass spectrometry (IMS). Thanamycin and thanapeptin detection by MALDI IMS are shown. (B) The middle panel presents the thanapeptin gene cluster with the position of the transposon insertions, and the modules encoded by the gene clusters and the prediction for the amino acids assembled. On the middle left, the partial spectrometry profile of the MALDI IMS of the SH-C52 and $R$. solani interaction is shown. (C) At the bottom the tentative thanapeptin structure obtained from tandem mass spectrometry data is presented. Dashed arrows indicate amino acids that are difficult to predict from genome information, and that needed to be resolved by mass spectrometry.
Indeed, the sequenced strain $P$. corrugata CFBP5454 was isolated because of its pathogenic properties (Licciardello et al., 2007). In contrast, Pseudomonas sp. SH-C52 was isolated because of its plant-beneficial and antagonistic properties (Mendes et al., 2011). For $P$. corrugata, regulation of cormycin and corpeptin production is under the control of an $\mathrm{N}$-acyl-homoserine-lactone quorum sensing system (Licciardello et al., 2012), for which the genes are conserved in strain SH-C52 (data not shown). For both, the quorum sensing system is located down-stream of the thana/corpeptin gene clusters. The different origin of these strains suggests that structurally identical secondary metabolites can have diverse functions, depending on the niche where they are produced. For instance they can fight off pathogen threats for certain plant niches, as is the case for thanamycin in protecting sugar beet seedlings, or are advantageous to occupy certain niches, as is the case for cormycin during infection of plants.

In addition to thanamycin and thanapeptin, Pseudomonas sp. SH-C52 produces a third LP with antimicrobial activity. Previously, brabantamides were shown to be active against specific Gram-positive bacteria (Reder-Christ et al., 2012; Schmidt et al., 2014). Here we report that brabantamide A also has activity against oomycetes. Interestingly, this compound has received considerable attention for the development of the synthetic phospholipase inhibitor darapladib, which is tested for treatment of atherosclerosis (Johnston et al., 2013). This highlights the importance of identifying novel LPs for the development of new medicines. In this respect it is interesting to note that in the genome of Pseudomonas sp. SH-C52 a putative fourth LP-NRPS gene cluster is present, with a yet unknown structure and function. Also an $m g o A$-like NRPS gene was identified in the genome of SH-C52. Although the mgo-operon was shown to be essential for mangotoxin production in mangopathogenic P. syringae strains (Arrebola et al., 2012), it was later demonstrated that the biosynthesis of mangotoxin occurs by means of the mbo-operon (Carrion et al., 2012). This suggests that MgoA likely has a regulatory function (Carrion et al., 2014). An orthologous gene cluster was shown to be essential for insect pathogenicity in $P$. entomophila, however, no pathogenicity factor or compound has yet been linked to this phenotype (ValletGely et al., 2010). The mgo-operons are not only present in pathogenic bacteria, but are widespread among Pseudomonas species, including species from the P. fluorescens clade (Loper et al., 2012). Since the product from MgoA, or the mgooperon, has not been deduced, the function of the mgo-operon 


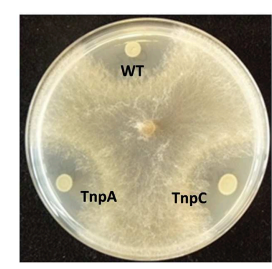

R. solani

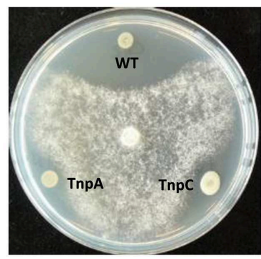

P. infestans

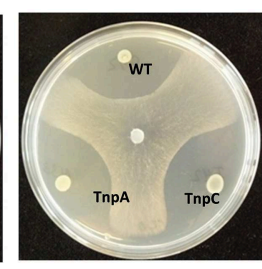

B. cinerea

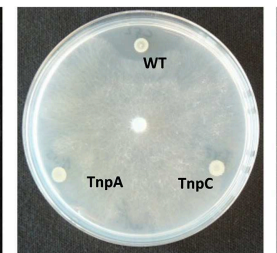

P. ultimum

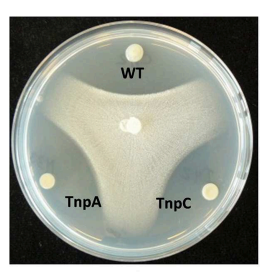

Geotrichum sp.

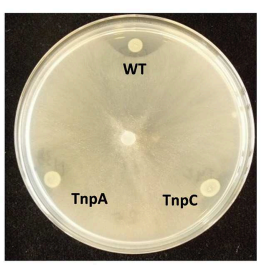

P. capsici
FIGURE 6 | Antagonistic activity of Pseudomonas sp. SH-C52. The wild-type (WT) and the thanapeptin mutants strains, Tn-tnpA (TnpA) and Tn-tnpC (TnpC) were tested in dual culture assays for activity against fungal plant pathogens (upper panel) and oomycete plant pathogens (lower panel).
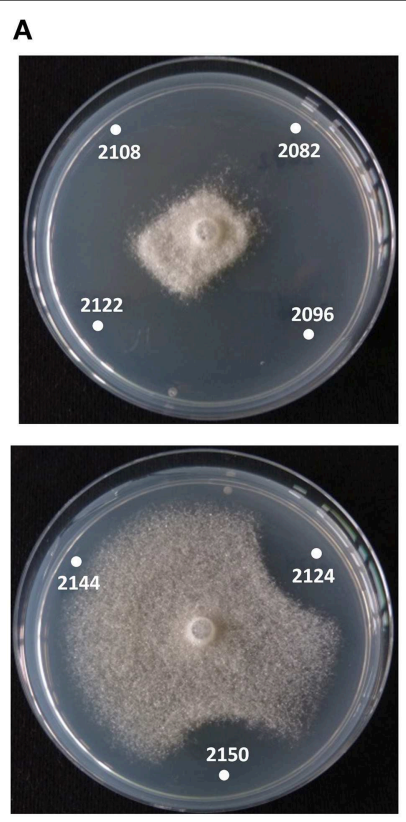

P. infestans
B

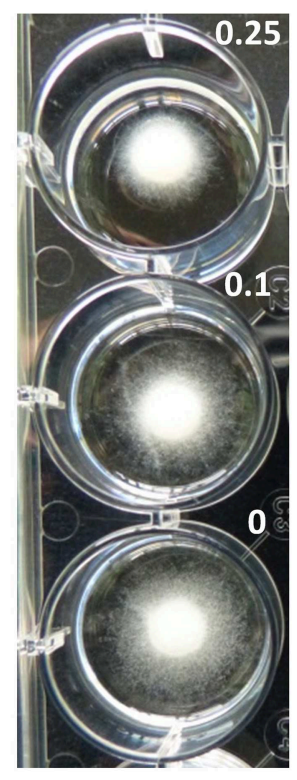

$2096 \mathrm{Da}$
FIGURE 7 | Activity of thanapeptin derivatives against Phytophthora infestans. (A) Activity of thanapeptin tested on plate. Numbers indicated in the pictures are the parent mass of the derivate tested in Da. (B) For the derivate of $2096 \mathrm{Da}$ the growth-inhibitory activity was tested in liquid broth, at different concentrations, indicated in the picture in $\mu \mathrm{g} / \mathrm{ml}$.

remains an intriguing question. The Mgo-product may act as a Pseudomonas specific switch for secondary metabolite production or as a genus- or species-specific regulator involved in different functions.
The production of secondary metabolites often comes at the expense of primary metabolism (Ruiz et al., 2010). Therefore, production needs to be tightly regulated in a temporal and spatial manner. Pseudomonas sp. SH-C52 has the ability to produce at least three and likely four structurally different LPs, each with structural variants. LPs have diverse natural functions in motility, biofilm formation, antibiosis, defense or virulence (Raaijmakers and Mazzola, 2012). These functions have to be strictly regulated and cannot be performed all at once. Some LPs are produced at the same time but may have different roles. This is the case for two LPs produced by Pseudomonas CMR12a, i.e., sessilin and orfamide that are produced together but involved in respectively biofilm formation and swarming. Regulation takes place by the fact that sessilin hampers the release of orfamide by co-precipitating with orfamide (D'Aes et al., 2014). Although we do see that thanamycin and thanapeptin can be produced simultaneously by Pseudomonas SH-C52 (Figure 5), we do not see the simultaneous production of the other two LPs. This suggests dissimilar regulatory pathways for the production of these LPs, possibly with negative and positive feedback loops. Three of the LPs produced by SH-C52 have antimicrobial activity in vitro, but it remains to be studied if these LPs also have antimicrobial activity in vivo. In this respect, future studies will focus on the identification of regulatory pathways and identification of specific extracellular cues that trigger the production of the structurally diverse LPs in SHC52 in interactions with diverse organisms encountered in the rhizosphere environment.

\section{Author Contributions}

MV designed and performed microbiological, molecular and chemical experiments, performed in silico genome analysis and drafted the manuscript. HM performed growth inhibition assays with $P$. infestans and experiments to test phospholipase activity. JW designed chemical experiments, helped in chemical analysis, and performed the chemistry and analysis on the thanapeptin structure, ED assisted in microbiological and molecular experiments. RM was involved in acquiring and analysing genome information. YS and HG purified brabantamide A for phospholipase and antimicrobial assays. PD designed chemical experiments and was involved in chemical imaging. JR supervised the work and was involved in the experimental design. All authors contributed to the writing of the manuscript and approved submission.

\section{Acknowledgments}

This research was financially supported by the Dutch BE-BASIC national research program.

\section{Supplementary Material}

The Supplementary Material for this article can be found online at: http://journal.frontiersin.org/article/10.3389/fmicb. 2015.00693 


\section{References}

Arrebola, E., Carrion, V. J., Cazorla, F. M., Perez-Garcia, A., Murillo, J., and De Vicente, A. (2012). Characterisation of the mgo operon in Pseudomonas syringae pv. syringae UMAF0158 that is required for mangotoxin production. BMC Microbiol. 12:10. doi: 10.1186/1471-2180-12-10

Bachmann, B. O., and Ravel, J. (2009). Chapter 8. Methods for in silico prediction of microbial polyketide and nonribosomal peptide biosynthetic pathways from DNA sequence data. Methods Enzymol. 458, 181-217. doi: 10.1016/S00766879(09)04808-3

Berendsen, R. L., Pieterse, C. M., and Bakker, P. A. (2012). The rhizosphere microbiome and plant health. Trends Plant Sci. 17, 478-486. doi: 10.1016/j.tplants.2012.04.001

Berti, A. D., and Thomas, M. G. (2009). Analysis of achromobactin biosynthesis by Pseudomonas syringae pv. syringae B728a. J. Bacteriol. 191, 4594-4604. doi: 10.1128/JB.00457-09

Blin, K., Medema, M. H., Kazempour, D., Fischbach, M. A., Breitling, R., Takano, E., et al. (2013). antiSMASH 2.0-a versatile platform for genome mining of secondary metabolite producers. Nucleic Acids Res. 41, W204-W212. doi: 10.1093/nar/gkt449

Carrion, V. J., Arrebola, E., Cazorla, F. M., Murillo, J., and De Vicente, A. (2012). The mbo operon is specific and essential for biosynthesis of mangotoxin in Pseudomonas syringae. PLoS ONE 7:e36709. doi: 10.1371/journal.pone. 0036709

Carrion, V. J., Van Der Voort, M., Arrebola, E., Gutierrez-Barranquero, J. A., De Vicente, A., Raaijmakers, J. M., et al. (2014). Mangotoxin production of Pseudomonas syringae pv. syringae is regulated by MgoA. BMC Microbiol. 14:46. doi: 10.1186/1471-2180-14-46

Catara, V. (2007). Pseudomonas corrugata: plant pathogen and/or biological resource? Mol. Plant Pathol. 8, 233-244. doi: 10.1111/j.1364-3703.2007.00391.x

D’Aes, J., De Maeyer, K., Pauwelyn, E., and Hofte, M. (2010). Biosurfactants in plant-Pseudomonas interactions and their importance to biocontrol. Environ. Microbiol. Rep. 2, 359-372. doi: 10.1111/j.1758-2229.2009.00104.x

D’Aes, J., Kieu, N. P., Leclere, V., Tokarski, C., Olorunleke, F. E., De Maeyer, K., et al. (2014). To settle or to move? The interplay between two classes of cyclic lipopeptides in the biocontrol strain Pseudomonas CMR12a. Environ. Microbiol. 16, 2282-2300. doi: 10.1111/1462-2920.12462

De Bruijn, I., De Kock, M. J., Yang, M., De Waard, P., Van Beek, T. A., and Raaijmakers, J. M. (2007). Genome-based discovery, structure prediction and functional analysis of cyclic lipopeptide antibiotics in Pseudomonas species. Mol. Microbiol. 63, 417-428. doi: 10.1111/j.1365-2958.2006.05525.x

Douzi, B., Filloux, A., and Voulhoux, R. (2012). On the path to uncover the bacterial type II secretion system. Philos. Trans R. Soc. Lond. B Biol. Sci. 367, 1059-1072. doi: 10.1098/rstb.2011.0204

Emanuele, M. C., Scaloni, A., Lavermicocca, P., Jacobellis, N. S., Camoni, L., Di Giorgio, D., et al. (1998). Corpeptins, new bioactive lipodepsipeptides from cultures of Pseudomonas corrugata. FEBS Lett. 433, 317-320. doi: 10.1016/S0014-5793(98)00933-8

Gross, H., and Loper, J. E. (2009). Genomics of secondary metabolite production by Pseudomonas spp. Nat. Prod. Rep. 26, 1408-1446. doi: 10.1039/b817075b

Haas, D., and Defago, G. (2005). Biological control of soil-borne pathogens by fluorescent pseudomonads. Nat. Rev. Microbiol. 3, 307-319. doi: 10.1038/nrmicro1129

Hassan, K. A., Johnson, A., Shaffer, B. T., Ren, Q., Kidarsa, T. A., Elbourne, L. D., et al. (2010). Inactivation of the GacA response regulator in Pseudomonas fluorescens Pf-5 has far-reaching transcriptomic consequences. Environ. Microbiol. 12, 899-915. doi: 10.1111/j.1462-2920.2009.02134.x

Johnston, C. W., Zvanych, R., Khyzha, N., and Magarvey, N. A. (2013). Nonribosomal assembly of natural lipocyclocarbamate lipoproteinassociated phospholipase inhibitors. Chembiochem 14, 431-435. doi: 10.1002/cbic.201200598

Kersten, R. D., Yang, Y. L., Xu, Y., Cimermancic, P., Nam, S. J., Fenical, W., et al. (2011). A mass spectrometry-guided genome mining approach for natural product peptidogenomics. Nat. Chem. Biol. 7, 794-802. doi: 10.1038/nchembio.684

King, E. O., Ward, M. K., and Raney, D. E. (1954). Two simple media for the demonstration of pyocyanin and fluorescin. J. Lab. Clin. Med. 44, 301-307.
Korotkov, K. V., Sandkvist, M., and Hol, W. G. (2012). The type II secretion system: biogenesis, molecular architecture and mechanism. Nat. Rev. Microbiol. 10, 336-351. doi: 10.1038/nrmicro2762

Latijnhouwers, M., Ligterink, W., Vleeshouwers, V. G., Van West, P., and Govers, F. (2004). A Galpha subunit controls zoospore motility and virulence in the potato late blight pathogen Phytophthora infestans. Mol. Microbiol. 51, 925-936. doi: 10.1046/j.1365-2958.2003.03893.x

Latijnhouwers, M., Munnik, T., and Govers, F. (2002). Phospholipase D in Phytophthora infestans and its role in zoospore encystment. Mol. Plant Microbe. Interact. 15, 939-946. doi: 10.1094/MPMI.2002.15.9.939

Li, M. H., Ung, P. M., Zajkowski, J., Garneau-Tsodikova, S., and Sherman, D. H. (2009). Automated genome mining for natural products. BMC Bioinformatics 10:185. doi: 10.1186/1471-2105-10-185

Li, R., Zhu, H., Ruan, J., Qian, W., Fang, X., Shi, Z., et al. (2010). De novo assembly of human genomes with massively parallel short read sequencing. Genome Res. 20, 265-272. doi: 10.1101/gr.097261.109

Licciardello, G., Bertani, I., Steindler, L., Bella, P., Venturi, V., and Catara, V. (2007). Pseudomonas corrugata contains a conserved $\mathrm{N}$-acyl homoserine lactone quorum sensing system; its role in tomato pathogenicity and tobacco hypersensitivity response. FEMS Microbiol. Ecol. 61, 222-234. doi: 10.1111/j.1574-6941.2007.00338.x

Licciardello, G., Strano, C. P., Bertani, I., Bella, P., Fiore, A., Fogliano, V., et al. (2012). N-acyl-homoserine-lactone quorum sensing in tomato phytopathogenic Pseudomonas spp. is involved in the regulation of lipodepsipeptide production. J. Biotechnol. 159, 274-282. doi: 10.1016/j.jbiotec.2011.07.036

Liu, W. T., Lamsa, A., Wong, W. R., Boudreau, P. D., Kersten, R., Peng, Y., et al. (2014). MS/MS-based networking and peptidogenomics guided genome mining revealed the stenothricin gene cluster in Streptomyces roseosporus. J. Antibiot. (Tokyo) 67, 99-104. doi: 10.1038/ja.2013.99

Liu, W. T., Yang, Y. L., Xu, Y., Lamsa, A., Haste, N. M., Yang, J. Y., et al. (2010). Imaging mass spectrometry of intraspecies metabolic exchange revealed the cannibalistic factors of Bacillus subtilis. Proc. Natl. Acad. Sci. U.S.A. 107, 16286-16290. doi: 10.1073/pnas.1008368107

Loper, J. E., Hassan, K. A., Mavrodi, D. V., Davis, E. W. 2nd., Lim, C. K., Shaffer, B. T., et al. (2012). Comparative genomics of plant-associated Pseudomonas spp.: insights into diversity and inheritance of traits involved in multitrophic interactions. PLoS Genet. 8:e1002784. doi: 10.1371/journal.pgen.1002784

Lugtenberg, B., and Kamilova, F. (2009). Plant-growth-promoting rhizobacteria. Annu. Rev. Microbiol. 63, 541-556. doi: 10.1146/annurev. micro.62.081307.162918

Marahiel, M. A., and Essen, L. O. (2009). Chapter 13. Nonribosomal peptide synthetases mechanistic and structural aspects of essential domains. Methods Enzymol. 458, 337-351. doi: 10.1016/S0076-6879(09)04813-7

Matthijs, S., Budzikiewicz, H., Schafer, M., Wathelet, B., and Cornelis, P. (2008). Ornicorrugatin, a new siderophore from Pseudomonas fluorescens AF76. Z. Naturforsch. C 63, 8-12. doi: 10.1515/znc-2008-1-202

Meijer, H. J., Hassen, H. H., and Govers, F. (2011). Phytophthora infestans has a plethora of phospholipase D enzymes including a subclass that has extracellular activity. PLOS ONE 6:e17767. doi: 10.1371/journal.pone.0017767

Mendes, R., Kruijt, M., De Bruijn, I., Dekkers, E., Van Der Voort, M., Schneider, J. H., et al. (2011). Deciphering the rhizosphere microbiome for disease-suppressive bacteria. Science 332, 1097-1100. doi: 10.1126/science. 1203980

Meyer, J. M., Geoffroy, V. A., Baida, N., Gardan, L., Izard, D., Lemanceau, P., et al. (2002). Siderophore typing, a powerful tool for the identification of fluorescent and nonfluorescent pseudomonads. Appl. Environ. Microbiol. 68, 2745-2753. doi: 10.1128/AEM.68.6.2745-2753.2002

Michelsen, C. F., Watrous, J., Glaring, M. A., Kersten, R., Koyama, N., Dorrestein, P. C., et al. (2015). Nonribosomal peptides, key biocontrol components for pseudomonas fluorescens In5, isolated from a greenlandic suppressive soil. MBio 6:e0079-15. doi: 10.1128/mBio.00079-15

Munnik, T., Arisz, S. A., De Vrije, T., and Musgrave, A. (1995). G protein activation stimulates phospholipase D signaling in plants. Plant Cell 7, 2197-2210. doi: 10.1105/tpc.7.12.2197

Overbeek, R., Olson, R., Pusch, G. D., Olsen, G. J., Davis, J. J., Disz, T., et al. (2014). The SEED and the Rapid Annotation of microbial genomes using 
Subsystems Technology (RAST). Nucleic Acids Res. 42, D206-D214. doi: 10.1093/nar/gkt1226

Owen, J. G., and Ackerley, D. F. (2011). Characterization of pyoverdine and achromobactin in Pseudomonas syringae pv. phaseolicola 1448a. BMC Microbiol. 11:218. doi: 10.1186/1471-2180-11-218

Raaijmakers, J. M., De Bruijn, I., Nybroe, O., and Ongena, M. (2010). Natural functions of lipopeptides from Bacillus and Pseudomonas: more than surfactants and antibiotics. FEMS Microbiol. Rev. 34, 1037-1062. doi: 10.1111/j.1574-6976.2010.00221.x

Raaijmakers, J. M., and Mazzola, M. (2012). Diversity and natural functions of antibiotics produced by beneficial and plant pathogenic bacteria. Annu. Rev. Phytopathol. 50, 403-424. doi: 10.1146/annurev-phyto-081211-172908

Reder-Christ, K., Schmidt, Y., Dorr, M., Sahl, H. G., Josten, M., Raaijmakers, J. M., et al. (2012). Model membrane studies for characterization of different antibiotic activities of lipopeptides from Pseudomonas. Biochim. Biophys. Acta 1818, 566-573. doi: 10.1016/j.bbamem.2011.08.007

Redondo-Nieto, M., Barret, M., Morrisey, J. P., Germaine, K., MartinezGranero, F., Barahona, E., et al. (2012). Genome sequence of the biocontrol strain Pseudomonas fluorescens F113. J. Bacteriol. 194, 1273-1274. doi: 10.1128/JB.06601-11

Ruiz, B., Chavez, A., Forero, A., Garcia-Huante, Y., Romero, A., Sanchez, M., et al. (2010). Production of microbial secondary metabolites: regulation by the carbon source. Crit. Rev. Microbiol. 36, 146-167. doi: $10.3109 / 10408410903489576$

Russell, A. B., Peterson, S. B., and Mougous, J. D. (2014). Type VI secretion system effectors: poisons with a purpose. Nat. Rev. Microbiol. 12, 137-148. doi: 10.1038/nrmicro3185

Scaloni, A., Dalla Serra, M., Amodeo, P., Mannina, L., Vitale, R. M., Segre, A. L., et al. (2004). Structure, conformation and biological activity of a novel lipodepsipeptide from Pseudomonas corrugata: cormycin A. Biochem. J. 384, 25-36. doi: 10.1042/BJ20040422

Schmidt, Y., Van Der Voort, M., Crusemann, M., Piel, J., Josten, M., Sahl, H. G., et al. (2014). Biosynthetic origin of the antibiotic cyclocarbamate brabantamide A (SB-253514) in plant-associated Pseudomonas. Chembiochem 15, 259-266. doi: $10.1002 /$ cbic. 201300527

Silby, M. W., Winstanley, C., Godfrey, S. A., Levy, S. B., and Jackson, R. W. (2011). Pseudomonas genomes: diverse and adaptable. FEMS Microbiol. Rev. 35, 652-680. doi: 10.1111/j.1574-6976.2011.00269.x

Siverio, F., Cambra, M., Gorris, M. T., Corzo, J., and Lopez, M. M. (1993). Lipopolysaccharides as Determinants of Serological Variability in Pseudomonas corrugata. Appl. Environ. Microbiol. 59, 1805-1812.

Strano, C. P., Bella, P., Licciardello, G., Fiore, A., Lo Piero, A. R., Fogliano, V., et al. (2014). Pseudomonas corrugata crpCDE is part of the cylic lipopeptide corpeptin biosynthetic gene cluster and is involved in bacterial virulence in tomato and in hypersensitive response in Nicotiana benthamiana. Mol. Plant Pathol. 175, 65-66. doi: 10.1111/mpp.12207
Tampakaki, A. P. (2014). Commonalities and differences of T3SSs in rhizobia and plant pathogenic bacteria. Front. Plant Sci. 5:114. doi: 10.3389/fpls.2014.00114

Thirkettle, J., Alvarez, E., Boyd, H., Brown, M., Diez, E., Hueso, J., et al. (2000). SB253514 and analogues; novel inhibitors of lipoprotein-associated phospholipase A2 produced by Pseudomonas fluorescens DSM 11579. I. Fermentation of producing strain, isolation and biological activity. J. Antibiot. (Tokyo) 53, 664-669. doi: 10.7164/antibiotics.53.664

Vallet-Gely, I., Opota, O., Boniface, A., Novikov, A., and Lemaitre, B. (2010). A secondary metabolite acting as a signalling molecule controls Pseudomonas entomophila virulence. Cell Microbiol. 12, 1666-1679. doi: 10.1111/j.14625822.2010.01501.x

Van Loon, L. C., Bakker, P. A., and Pieterse, C. M. (1998). Systemic resistance induced by rhizosphere bacteria. Annu. Rev. Phytopathol. 36, 453-483. doi: 10.1146/annurev.phyto.36.1.453

Van Wees, S. C., Van Der Ent, S., and Pieterse, C. M. (2008). Plant immune responses triggered by beneficial microbes. Curr. Opin. Plant Biol. 11, 443-448. doi: 10.1016/j.pbi.2008.05.005

Vassilev, V., Lavermicocca, P., Di Giorgio, D., and Iacobellis, N. S. (1996). Production of syringomycins and syringopeptins by Pseudomonas syringae pv. atrofaciens. Plant Pathol. 45, 316-322. doi: 10.1046/j.1365-3059.1996. d01-126.x

Watrous, J., Roach, P., Alexandrov, T., Heath, B. S., Yang, J. Y., Kersten, R. D., et al. (2012). Mass spectral molecular networking of living microbial colonies. Proc. Natl. Acad. Sci. U.S.A. 109, E1743-E1752. doi: 10.1073/pnas.1203689109

Weller, D. M. (2007). Pseudomonas biocontrol agents of soilborne pathogens: looking back over 30 years. Phytopathology 97, 250-256. doi: 10.1094/PHYTO97-2-0250

Wu, X., Monchy, S., Taghavi, S., Zhu, W., Ramos, J., and Van Der Lelie, D. (2011). Comparative genomics and functional analysis of niche-specific adaptation in Pseudomonas putida. FEMS Microbiol. Rev. 35, 299-323. doi: 10.1111/j.15746976.2010.00249.x

$\mathrm{Xu}, \mathrm{Z}$., and Hao, B. (2009). CVTree update: a newly designed phylogenetic study platform using composition vectors and whole genomes. Nucleic Acids Res. 37, W174-W178. doi: 10.1093/nar/gkp278

Conflict of Interest Statement: The authors declare that the research was conducted in the absence of any commercial or financial relationships that could be construed as a potential conflict of interest.

Copyright ( 2015 Van Der Voort, Meijer, Schmidt, Watrous, Dekkers, Mendes, Dorrestein, Gross and Raaijmakers. This is an open-access article distributed under the terms of the Creative Commons Attribution License (CC BY). The use, distribution or reproduction in other forums is permitted, provided the original author(s) or licensor are credited and that the original publication in this journal is cited, in accordance with accepted academic practice. No use, distribution or reproduction is permitted which does not comply with these terms. 